\title{
science \\ Presidential address: How to cope with the present environment of scholarly journal publishing
}

\author{
Sun Huh
}

Department of Parasitology and Institute of Medical Education, College of Medicine, Hallym University, Chuncheon, Korea

It is an honor for me to have the opportunity to serve as the 4th President of the Korean Council of Science Editors (KCSE) from January 2020 to January 2023. The KCSE, which was launched in 2011, is a unique organization, the membership of which includes representatives of publishers of scholarly journals in all scientific areas and journal publishing companies in Korea.

\section{Organizations of Science Editors throughout the World}

Worldwide, some organizations of science editors are organized at the country level, with examples including organizations in Vietnam (Vietnamese Council of Science Editors), Indonesia (Indonesian Association of Scientific Journal Editors) [1], and Brazil (Associação Brasileira de Editores Científicos). Additionally, Bulgaria, Croatia, Italy, Mexico, Peru, Russia, Turkey, and Vietnam have regional chapters of the European Association of Science Editors. Other regional organizations of science editors include the Council of Science Editors (CSE) in North America; the Council of Asian Science Editors (CASE) in East, Southeast, and South Asia; and the Asian Council of Science Editors in the Middle East and South Asia. Some other country-level organizations are limited to the medical field, such as the Korean Association of Medical Journal Editors.

\section{Tasks of the KCSE}

Received: January 23, 2020 Accepted: January 31,2020

Correspondence to Sun Huh shuh@hallym.ac.kr

ORCID

Sun Huh

https://orcid.org/0000-0002-8559-8640
In contrast to other country-level organizations of science editors, the KCSE plays two unique roles: first, publishing a scholarly journal entitled Science Editing, and second, managing the Korea Manuscript Editors Certification. Science Editing, which was launched in 2014, is the official journal of the KCSE and CASE. It has been indexed in the Web of Science Core Collection as part of the Emerging Sources Citation Index since 2017 [2] and in Scopus since 2018 [3]. There are only a few international journals specifically for science editors: Science Editing, European Science Editing, which has been published since 1975 by the European Association of Science Editors; and Science Editor, which has been published since 1978 by the CSE. Science 
Editing publishes articles on practical aspects of journal publishing and editing, aiming to help editors and publishers work more efficiently with up-to-date knowledge and skills. The Korea Manuscript Editors Certification was introduced in 2017 [4]. It has benchmarked the training and certificate systems for manuscript editors of the Board of Editors in the Life Sciences (BELS), American Medical Writers Association, and CSE. Although it is still in its roll-out stage, this certification system will bolster the professional competency of manuscript editors in Korea.

Beyond these two unique services, the main job of KCSE is to provide training for editors, manuscript editors, and staff of publishing companies on editing, manuscript editing, and research and publication ethics. Another exciting domain of the KCSE's activities is its contributions to the CASE, which provides assistance to editors from various Asian countries by holding annual or biannual conferences and workshops [5]. The KCSE took on another new responsibility in September 2019, when it became responsible for maintaining the Scopus Expert Content Selection \& Advisory Committee-Korea under an agreement with Elsevier; the role of this committee is to recommend journals in Korea to the Scopus Content Selection and Advisory Board [6].

\section{The Recent Shifts Surrounding Scientific Journal Publishing in Korea}

In Korea, the Korean Federation of Science and Technology Societies supports scientific journal publishing with a budget of about 4 million dollars per year, which is distributed according to the results of journal evaluations. As only $70 \%$ of journals that apply receive these funds, additional efforts must be made to increase the budget for supporting scientific journals. In order to increase the budget, it is necessary to persuade government officials and legislators with evidence of

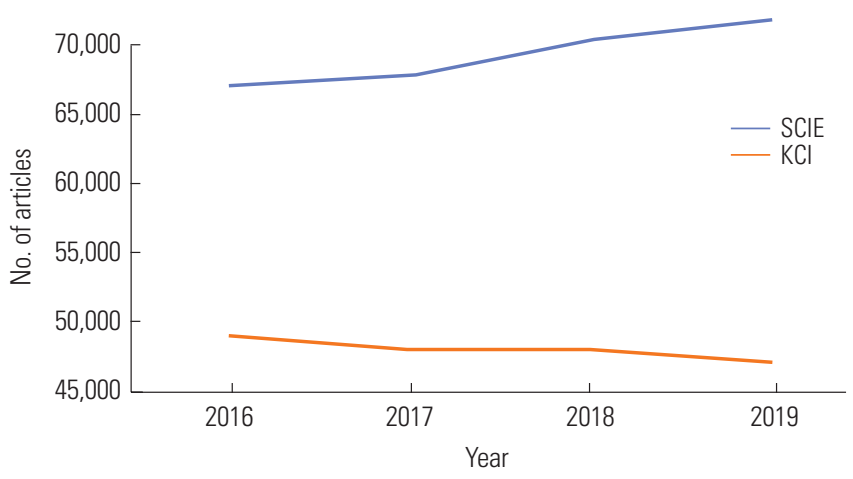

Fig. 1. Change in the number of scientific articles by Korean authors in Science Citation Index Expanded (SCIE) and Korea Citation Index (KCI) journals from 2016 to 2019 [cited 2020 Jan 21]. positive effects on the promotion of journals.

In recent years, the number of articles in Science Citation Index Expanded (SCIE) journals by Korean authors has steadily increased, while the number of scientific articles in the Korea Citation Index (KCI), which is the abstract database of Korean scholarly journals, showed a year-by-year decrease (Fig. 1). A comparison among fields is presented in Fig. 2; a decrease in the number of articles was found in the medicine, natural sciences, and agriculture. These findings indicate that Korean scientists already publish a higher number of articles in SCIE journals than in KCI journals. Because about $120 \mathrm{KCI}$ journals are indexed in SCIE in January 2020, the number of articles in non-SCIE KCI journals may be much lower.

Furthermore, the number of KCI-indexed scientific journals has increased from year to year. Thus, it has become more difficult for scientific journal editors in Korea to attract manuscripts, even from Korean authors. The research competence and writing ability of Korean scientists have steadily increased, in correspondence with the increase of Korea's research and development (R\&D) budget, which is ranked 5th in the world [7]. The R\&D budget of Korea was 676 billion US dollars in 2018, and the ratio of the R\&D budget to national gross domestic product (4.55\%) was the highest in the world [8]. If scientific journals from Korea are not indexed in international databases, this trend will inevitably continue. Editors and publishers should do their best to survive in the journal market.

Another international issue may also affect local journals. In Korea, most journals are published by academic societies or non-profit institutes; therefore, journals are generally open access, with no article processing charge or a minimum charge, and they own the copyright of articles. Plan S, which mandates all scholarly publications from research funded by Plan S funders to be published in open access journals or platforms will start in 2021. Since most scholarly journals pub-

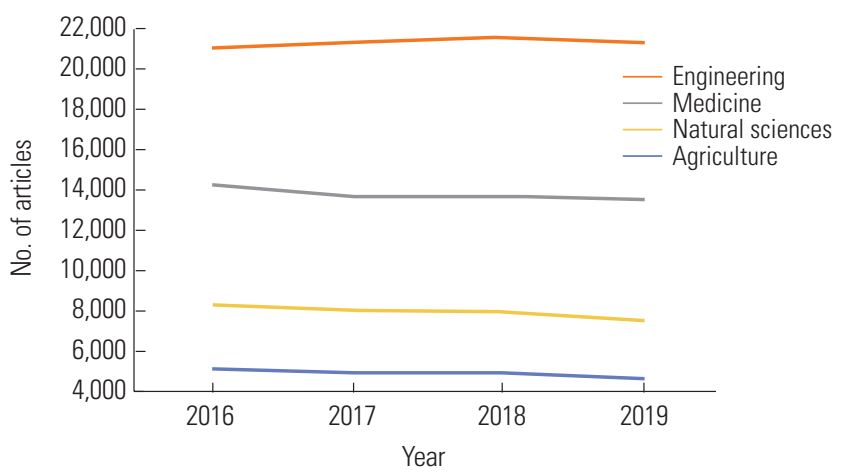

Fig. 2. Change in the number of articles in the Korea Citation Index database according to research field from 2016 to 2019 [cited 2020 Jan 21]. 
lished in Korea is open access without an embargo or deposited in the public repositories, it will be possible to recruit manuscripts supported by Plan S funders including the European Research Council and UK Research and Innovation [9].

\section{Tasks for Editors to Promote Their Journals to International Standards}

In accordance with these changes in the domestic and global environment of journal publishing, the members of the KCSE who are journal editors should prepare to recruit numerous higher-quality manuscripts from Korea or other countries. They should provide more reliable and better services to authors, reviewers, and readers by following the best practices of international-level journals. I suggest the following three tasks as initial steps that editors can take to promote their journals to the top tier. First, they should provide precise and detailed information on the journal's adherence to the Principles of transparency and best practice in scholarly publishing, 3rd version (https://doaj.org/bestpractice). Second, if the journal has an open access policy, it should be registered with the Directory of Open Access Journals (https://doaj.org). Finally, the journal's full-text files should be deposited in the National Library of Korea for digital archiving, which guarantees continuous access to journal content, even if the journal is discontinued at any time.

To help our members who are journal editors carry out these tasks with the best of their, the KCSE's current activities, which already provide a solid foundation for excellence, will continue during my 3-year term. I hope that the work of the KCSE will be helpful for journal editors who devote themselves to editing on a voluntary basis.

\section{Conflict of Interest}

Sun Huh is the President of the Korean Council of Science Editors from January 2020 to January 2023.

\section{References}

1. Wiryawan KG. Establishment of the Indonesian Association of Scientific Journal Editors. Sci Ed 2019;6:148-50. https://doi.org/10.6087/kcse.176

2. Kim K. Science Editing is now indexed in the Emerging Sources Citation Index. Sci Ed 2017;4:55. https://doi.org/ $10.6087 / \mathrm{kcse} .95$

3. Kim K. Science Editing is indexed in the Scopus. Sci Ed 2018;5:1. https://doi.org/10.6087/kcse.110

4. Yi HJ, Chang JH, Seo YJ. Analysis of the results of the first implementation of the Korea Manuscript Editors Certification. Sci Ed 2017;4:34-8. https://doi.org/10.6087/kcse.87

5. Yoo S. The 5th Asian Science Editors' Conference and Workshop 2018. Sci Ed 2018;5:162-4. https://doi.org/10.6087/kcse. 144

6. Kim H. History of Scopus Expert Content Selection and Advisory Committee of Korea. Sci Ed 2020;7:6-10. https:// doi.org/10.6087/kcse.183

7. Organization for Economic Cooperation and Development. Research and Development Statistics: gross domestic expenditure on R-D by sector of performance and source of funds. OECD Science, Technology and R\&D Statistics (database) [Internet]. Paris: OECD iLibrary; 2020 [cited 2020 Jan 21]. Available from: https://doi.org/10.1787/data00189-en

8. Organization for Economic Cooperation and Development. Gross domestic spending on R\&D (indicator) [Internet]. Paris: OECD iLibrary; 2020 [cited 2020 Jan 21]. Available from: https://doi.org/10.1787/d8b068b4-en

9. Science Europe. Plan-S: principles and implementation [Internet]. Brussels: Science Europe; 2019 [cited 2020 Jan 21]. Available from: https://www.coalition-s.org/addendum-to-the-coalition-s-guidance-on-the-implementation-of-plan-s/principles-and-implementation/ 